\title{
Evaluation of IL-8-Concentrations in Plasma and Lysed EDTA-Blood in Healthy Neonates and Those with Suspected Early Onset Bacterial Infection
}

\author{
THORSTEN W. ORLIKOWSKY, FELIX NEUNHOEFFER, RANGMAR GOELZ, MARTIN EICHNER, \\ CHRISTINE HENKEL, MANFRED ZWIRNER, AND CHRISTIAN F. POETS \\ Department of Neonatology [T.W.O., F.N., R.G., C.F.P.], University Children's Hospital, 72076 Tübingen, \\ Germany; Department of Medical Biometry [M.E.], 72070 Tübingen, Germany; and University Hospital of \\ Obstetrics and Gynecology [C.H., M.Z.], 72076 Tübingen, Germany
}

\begin{abstract}
Plasma IL-8 is a diagnostic parameter of early-onset bacterial infection (EOBI) in neonates but has a short half-life. The detergent-lysed whole-blood (DLWB) IL-8 consists of both extracellular and cell-bound IL-8. The objective of this study was to investigate kinetics of plasma and DLWB IL-8 in healthy newborns and those with suspected EOBI and to test the hypothesis that determination of DLWB IL-8 results in higher sensitivity for EOBI detection. Sixty-one neonates with clinical and serologic signs of EOBI composed the study group; 188 neonates with risk factors but without EOBI served as control subjects. IL-8 concentrations were determined in plasma and DLWB. In the control group, DLWB IL-8 concentrations were 280-fold higher $(9599 \mathrm{pg} / \mathrm{mL}$; SD 4433$)$ up to $24 \mathrm{~h}$ post partum than corresponding plasma levels (34.2 pg/mL; SD 18.1). The sensitivity of DLWB versus plasma IL-8 for EOBI was 0.97 versus 0.71 after $6 \mathrm{~h}$ and 0.70 versus 0.32 after $24 \mathrm{~h}$. Corresponding
\end{abstract}

\section{ABSTRACT}

values for specificity were 0.95 versus 0.90 after $6 \mathrm{~h}$ and 0.92 versus 0.99 after $24 \mathrm{~h}$. After $24 \mathrm{~h}$, the negative predictive value for DLWB versus plasma IL-8 was 0.80 versus 0.66 . DLWB IL-8 showed a higher sensitivity for EOBI within $6 \mathrm{~h}$ after first clinical suspicion than plasma IL-8. It also remained elevated longer. Our results suggest that DLWB IL-8 results in a higher sensitivity for EOBI. (Pediatr Res 56: 804-809, 2004)

CRP, C-reactive protein

Abbreviations

DLWB, detergent-lysed whole blood

EOBI, early-onset bacterial infection

I/T ratio, immature to total neutrophil ratio

NPV, negative predictive value

PPV, positive predictive value

ROC, receiver operator characteristics
Neonates are susceptible to infections (1). The differential diagnosis of early-onset bacterial infection (EOBI) therefore must always be present for the neonatologist, regardless of how minor, unexpected, or discrete the clinical symptoms. EOBI is usually defined as occurring up to $72 \mathrm{~h}$ after birth (2) and is associated with a high morbidity and mortality risk (1). The nonspecific clinical signs as well as the currently established biochemical and hematologic parameters have their diagnostic limitations $(3,4)$ [reviewed in $(5,6)$ ].

Plasma IL-8 is an appreciated, highly predictive, and easily accessible chemokine to detect EOBI (7). IL-8 secretion is not limited to infections $(8-10)$, yet it occurs within $1-3 \mathrm{~h}$ of endotoxin challenge (11). As with most cytokines, its plasma

Received October 30, 2003; accepted May 5, 2004

Correspondence: Thorsten W. Orlikowsky, M.D.,Univ.-Kinderklinik Tübingen, Calwerstrasse 7, 72076 Tübingen, Germany; e-mail: thorsten.orlikowsky@med.uni-tuebingen.de

DOI: 10.1203/01.PDR.0000141523.68664.4A half-life is short $(<4 \mathrm{~h})(12,13)$. Circulating IL-8, which can be detected in plasma or serum via immunoassay, is immediately bound to two distinct high-affinity IL- 8 receptors that are abundantly present on neutrophils before internalization and degradation $(14,15)$. Therefore, plasma IL-8 reflects only a small portion of the total IL-8 blood pool, because the majority is cell associated (16-18).

Cell association is enhanced by chemokine binding, nonIL-8-specific receptors. These have been identified on various cell types (19), including the Duffy antigen-related chemokine receptors (16), presented on erythrocytes. Duffy antigenrelated chemokine-ligated IL-8 is biologically inactive to neutrophils but has the ability to recirculate, because the receptor may be ligated by other cytokines $(16,17)$ or pathogens $(20,21)$.

Cell-associated IL-8 can be determined by lysing red blood cells with a detergent. Data from adult patients with sepsis 
suggested that detergent-lysed whole blood (DLWB) IL-8; i.e. cell-bound and extracellular IL-8, obtained by cell lysis, may provide additional information for the assessment of bacterial infection $(21,22)$. Therefore, the objective of this study was to evaluate IL- 8 kinetics in newborns with and without EOBI in DLWB and plasma. We speculated that DLWB IL- 8 may have a higher sensitivity and specificity for EOBI detection than plasma IL-8.

\section{METHODS}

Patients. Neonates who were admitted consecutively and met inclusion criteria for the study were enrolled with institutional ethics committee approval and parental consent. For determination of the reference range of DLWB IL-8, blood was collected from neonates who had risk factors for EOBI but no clinical signs or subsequent laboratory changes and underwent blood testing. To exclude EOBI, blood was drawn at 6, 24, and 48-60 $\mathrm{h}$ post partum in addition to close observation by experienced neonatologists at least three times per day. In addition, blood was collected from neonates with EOBI as defined below. IL- 8 blood samples were obtained before and after antibiotic treatment.

All blood samples were processed and analyzed within $2 \mathrm{~h}$. A prerequisite was a nonhemolytic sample, which mostly was obtained by venipuncture. Blood specimens that were macroscopically hemolytic or processed after $>2 \mathrm{~h}$ were excluded.

Definition of bacterial infection. A diagnosis of EOBI was based on the presence of at least two of the following criteria within the first $72 \mathrm{~h}$ of life (23): one or more clinical signs compatible with EOBI, plus a consecutive elevation of CRP $>10 \mathrm{mg} / \mathrm{L}$ within $24 \mathrm{~h}$ after first clinical suspicion, or positive blood culture results. On the basis of previous studies (23), clinical signs were defined as follows: fever $\left(\geq 37.8^{\circ} \mathrm{C}\right.$ rectal $)$, hypothermia $\left(\leq 36.5^{\circ} \mathrm{C}\right)$, temperature instability $\left(\geq 1.5^{\circ} \mathrm{C}\right)$, pallor, grayish skin color, poor perfusion (capillary refill $>2 \mathrm{~s}$ ), tachypnea ( $>60$ respirations per minute at rest), dyspnea (grunting, nasal flaring, retractions), respiratory insufficiency, apnea, rising fraction of inspired oxygen in previously stable neonate, arterial hypotension (mean arterial blood pressure $<37 \mathrm{~mm} \mathrm{Hg}$ ), muscular hypotonia, irritability, hyperexcitability, neck stiffness, and lethargy.

The CRP cutoff has been used for clinical purposes in our institution for many years according to previous investigations (24). Neonates who did not meet criteria for culture-proven or clinical infection were considered noninfected.

Workup program for suspected $\mathrm{EOBI}$. Indications for close clinical observation and our blood screening program were one or a combination of the following criteria: history of amniotic infection, maternal leukocytosis $\left(>12,000\right.$ granulocytes $\left./ \mathrm{mm}^{3}\right)$, and/or maternal CRP elevation to $>10 \mathrm{mg} / \mathrm{L}$ after exclusion of infectious foci unrelated to the fetus (gastrointestinal or urinary tract infections); fetal tachycardia ( $>160$ beats/min); prolonged rupture of membranes ( $\geq 12 \mathrm{~h}$ ) in the absence of labor; maternal fever (rectal temperature $\geq 38.0^{\circ} \mathrm{C}$ ); and foulsmelling amniotic fluid. Growth of group B streptococci in vaginal smear was routinely screened in case of prolonged rupture of membrane.
Sample processing and detection of IL-8. Plasma IL-8 concentrations were detected in lithium-heparin-coated tubes. Results were available after $50 \mathrm{~min}$. Twenty-five microliters of plasma was diluted with $100 \mu \mathrm{L}$ (1:5) sample diluent (I8; DPC Biermann, Bad Nauheim, Germany). The detergent concentration had previously been optimized to lyse blood cells without affecting the binding of the analyte to the assay antibody (17) (Immulite; DPC Biermann). The detection limit of plasma IL-8 was $2 \mathrm{pg} / \mathrm{mL}$ (standardized in accordance with the National Institute for Biologic Standards and Controls Reference Preparation 89/520) and was calibrated to $7500 \mathrm{pg} / \mathrm{mL}$. Inter- and intra-assay variations for plasma and DLWB IL-8 were $<5 \%$ at $100 \mathrm{pg} / \mathrm{mL}$ and $15,000 \mathrm{pg} / \mathrm{mL}$, respectively. According to an analysis using receiver operator characteristics (ROC) curves, the threshold for IL-8 plasma concentration was set to 60 $\mathrm{pg} / \mathrm{mL}$.

Native EDTA-blood, obtained for routine hematologic workup, served as a source for DLWB IL-8. For a single determination, a total volume of $50 \mu \mathrm{L}$ of whole blood was required. A blood cell lysate was immediately prepared from each EDTA-blood sample: a 0.05-mL aliquot of EDTA-blood was well mixed with $0.05 \mathrm{~mL}$ of lysis solution (buffered solution with detergent; Milenia Biotec, Bad Nauheim, Germany) and incubated in stoppered $1.5-\mathrm{mL}$ polypropylene tubes for $5 \mathrm{~min}$ at room temperature, as previously described (17). The resulting lysate was used for IL- 8 measurements without further centrifugation via chemiluminescence immunoassay (Immulite test code I8; DPC Biermann), performed on a random-access fully automated assay suitable for $24 \mathrm{~h}$. Results were usually available within 50 min after blood sampling.

Biochemical and hematologic determinations. White blood cell count (determined in EDTA-blood) was performed on a fully automated cell counter (Coulter Counter T660, Krefeld, Germany). The immature neutrophils:total neutrophils ratio (I/T ratio) served as a neutrophil index, differentiated with microscopy by experienced technicians, and was calculated as the sum of the nonsegmented neutrophil granulocytes divided by the sum of all granulocytes. A segmented neutrophil granulocyte was defined by at least one indentation of the nucleus to less than one third of the maximal nuclear diameter. An I/T ratio $\geq 0.2$ was considered elevated. CRP was measured by enzyme sandwich immunoassay (Vitros 250; Ortho Diagnostics, Rochester, NY). Intra- and interassay variations were $<5 \%$. The threshold was set to $10 \mathrm{mg} / \mathrm{L} \mathrm{(7).}$

Statistical analysis. For IL-8 in DLWB and plasma, CRP and I/T ratio, specificity, sensitivity, positive predictive value (PPV), and negative predictive value (NPV), as well as the appropriate $95 \%$ confidence intervals, were calculated. ROC curves were constructed to describe the relationship between the sensitivity and the false-positive rate $(1-$ specificity) for different parameters (25). Choosing optimal cut-off points from ROC curves would allow for the detection of almost all cases with true-positive findings (high sensitivity) with a minimum number of false-positive results (high specificity).

Cytokine concentrations are shown as Box-Whisker plots. Data were grouped; results obtained between 0 and $6 \mathrm{~h}$ are depicted as $6 \mathrm{~h}$; results obtained between 6 and $12 \mathrm{~h}$ are depicted as $12 \mathrm{~h}$; those obtained between 24 and $36 \mathrm{~h}$ are 
depicted as $36 \mathrm{~h}$, etc. For the comparison of healthy neonates and those with EOBI within the same interval, the $t$ test was applied, using the decadic logarithm of the measurements. A $p$ $<0.05$ was defined as statistically significant. All charts were created with the help of software (SigmaPlot 2000; SPSS, Chicago, IL).

\section{RESULTS}

Patients. Serologic and clinical follow-up data were complete for 249 neonates with pre-, peri-, or postnatal risk factors and/or symptoms of EOBI. Twenty-four additional neonates had to be excluded because of incomplete records $(n=13)$ or simultaneous presence of other diseases potentially causing elevated IL-8 levels, such as chromosomal abnormalities or measurements after surgery $(n=11)$. The groups comprised 188 neonates without EOBI and 61 who met criteria for EOBI. Latter patients were discharged without the diagnosis of other inflammatory diseases. Positive blood cultures were found only in two of these (Streptococcus group B and Staphylococcus aureus). Four blood cultures were positive for Staphylococcus epidermidis, which were considered contaminated.

Patient characteristics are shown in Table 1. We found 67\% male neonates in the EOBI group, compared with $49 \%$ in the reference group $(p<0.05)$. Prenatal risk factors such as maternal fever (3.5 versus 0\%), pathologic cardiotocograph (CTG) (21 versus. 9\%), and fetal tachycardia (12 versus. $4 \%)$ were seen more frequently in the EOBI group. A total of $24.5 \%$ (15 of 61) neonates with EOBI were positive for group B streptococci in ear and/or throat. All patients (61 of 61) in the EOBI group received antibiotics according to our institutional standards (mean duration: $8 \mathrm{~d}$; SD 2.8), compared with $4.8 \%$ (9 of 188) of reference group infants. Because the suspicion of EOBI did not hold (CRP $<10 \mathrm{mg} / \mathrm{L}$, negative blood culture), treatment was discontinued after $1.6 \mathrm{~d}$ (SD 0.5) in the latter group; these neonates were regarded as noninfected.

IL-8 kinetics in noninfected neonates. Plasma IL-8 concentrations were $<60 \mathrm{pg} / \mathrm{mL}$ throughout and independent of postnatal age, with a mean of $34.2 \mathrm{pg} / \mathrm{mL}$ (SD 18.1) in the first $6 \mathrm{~h}$ and $30.5 \mathrm{pg} / \mathrm{mL}$ (SD 13.3) after $60 \mathrm{~h}$. DLWB IL-8 concentrations followed postnatal age-dependent kinetics. Compared with plasma, they were elevated 200 - to 300 -fold. In the first $24 \mathrm{~h}$ after birth, DLWB IL-8 concentrations increased from $9599 \mathrm{pg} / \mathrm{mL}$ (mean; SD 4433) after $6 \mathrm{~h}$ to $12179 \mathrm{pg} / \mathrm{mL}$ (SD 3849) after $24 \mathrm{~h}$ but decreased to $6289 \mathrm{pg} / \mathrm{mL}$ (SD 2104; $p<$ 0.05 versus $24 \mathrm{~h}$ ) after $48 \mathrm{~h}$ and to $5181 \mathrm{pg} / \mathrm{mL}$ (SD 2761) after $60 \mathrm{~h}$ (Fig. 1). For a cutoff of $60 \mathrm{pg} / \mathrm{mL}$ in plasma, ROC analysis

Table 1. Patient characteristics

\begin{tabular}{lcc}
\hline & EOBI & Control \\
\hline Neonates $(n)$ & 61 & 188 \\
$\begin{array}{l}\text { Postnatal age at time of } \\
\quad \text { clinical suspicion (h) }\end{array}$ & 7.53 & \\
& & \\
Male & SD 6.21 & $92(48.9 \%)$ \\
Gestational age [d; & $41(67.2 \%)$ & $275(231-294)$ \\
$\quad$ median (range)] & $282(231-288)$ & $3921(2490-4460)$ \\
$\begin{array}{l}\text { Birth weight [g; median } \\
\text { (range) }\end{array}$ & $3567(2390-4850)$ & \\
\hline
\end{tabular}

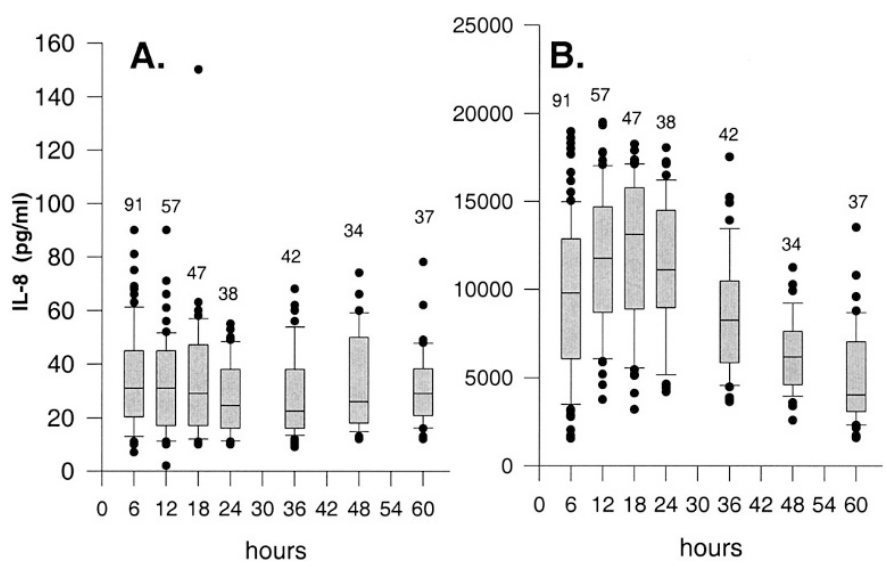

Figure 1. Kinetics of IL-8 in plasma $(A)$ and DLWB $(B)$ in 188 noninfected neonates.

revealed a sensitivity of $71 \%$ and a specificity $91 \%$; for 18000 $\mathrm{pg} / \mathrm{mL}$ in DLWB, a sensitivity of $97 \%$ and a specificity of $95 \%$ was found in the first $6 \mathrm{~h}$ after birth (Table 2).

Kinetics of IL-8 in EOBI. In the EOBI group, IL-8 concentrations in plasma $(142.4 \mathrm{pg} / \mathrm{mL}$; SD 111.6; $p<0.05$ versus noninfected group) and DLWB (38620 pg/mL; SD 23197 $\mathrm{pg} / \mathrm{mL} ; p<0.05$ versus noninfected group) were already elevated immediately after birth (Fig. 2). Whereas plasma IL-8 declined after $18 \mathrm{~h}$ (NS versus noninfected group), the levels in DLWB showed a prolonged period of elevation, lasting for another $\sim 12 \mathrm{~h}(p<0.05$ versus noninfected group). The sensitivity, specificity, PPV, and NPV for DLWB IL-8 at first clinical suspicion of infection are shown in Table 2 in comparison with plasma IL-8, CRP, and I/T ratio. ROC curves for IL-8 and CRP at 6, 12, and $24 \mathrm{~h}$ are displayed in Figure 3. Correlation between plasma and DLWB IL-8 was poor $(r<$ $0.35, \mathrm{NS})$.

In neonates with EOBI, the sensitivity of IL-8 in DLWB $(>18,000 \mathrm{pg} / \mathrm{mL}$ ) was $97 \%$ (34 of 35), compared with $71 \%$ $(>60 \mathrm{pg} / \mathrm{mL} ; 25$ of 35$)$ in plasma. The CRP had a sensitivity of only $14 \%$ ( 5 of 35 ) in the first $6 \mathrm{~h}$. The best sensitivity for EOBI $(100 \%$; 35 of 35$)$ was achieved by the combination of DLWB IL-8 and CRP. In neonates who were evaluated during the first $12 \mathrm{~h}$, DLWB IL-8 detected EOBI with a sensitivity of 93\% (95\% confidence interval: $87-99 \%$ ) versus plasma IL-8 of $70 \%(60-80 \%)$ and a specificity of $89 \%(82-96 \%)$ versus $93 \%$ (87-99\%). After 18 h, the sensitivity of DLWB IL-8 was $79 \%$ (15 of 19) versus $32 \%$ (6 of 19) in plasma, and the specificity was $87 \%$ (79-95\%) versus $96 \%$ (91-100\%). Sensitivity and specificity of CRP to detect EOBI increased over time. I/T ratio showed a low sensitivity of $14 \%(8-20 \%)$ to detect EOBI after $6 \mathrm{~h}$, increasing to $40 \%(30-50 \%)$ after $12 \mathrm{~h}$ but declining again to $20 \%(10-30 \%)$ after $24 \mathrm{~h}$ (Table 3, Fig. 3). In our study group (prevalence 0.245 ), the NPV of DLWB IL-8 after $24 \mathrm{~h}$ was higher than that of plasma IL-8 (80 versus $66 \%$; Table 3 ).

\section{DISCUSSION}

Investigating the suitability of DLWB compared with plasma IL-8 as an early marker of EOBI, we found 200- to 300 -fold increased levels for the former compared with the 
Table 2. Diagnostic accuracy of plasma and DLWB IL-8,CRP, and IT ratio within $6 \mathrm{~h}$ after first suspicion of EOBI

\begin{tabular}{lcccc}
\hline & DLWB & IL-8 plasma & CRP & I/T ratio \\
& IL-8 $>18000 \mathrm{pg} / \mathrm{mL}$ & $>60 \mathrm{pg} / \mathrm{mL}$ & $10 \mathrm{mg} / \mathrm{L}$ & $14(8-20)$ \\
\hline Sensitivity (\%) & $97(94-100)$ & $71(63-79)$ & $14(8-20)$ & $10(97-100)$ \\
Specificity (\%) & $95(91-99)$ & $90(85-95)$ & $100(90-100)$ & $71(63-79)$ \\
PPV (\%) & $87(81-93)$ & $74(66-82)$ & $100(97-100)$ & $75(67-83)$ \\
NPV (\%) & $99(97-100)$ & $89(86-92)$ & $75(67-83)$ & \\
\hline
\end{tabular}

Numbers in parentheses are exact $95 \%$ confidence intervals based on binomial sampling process.

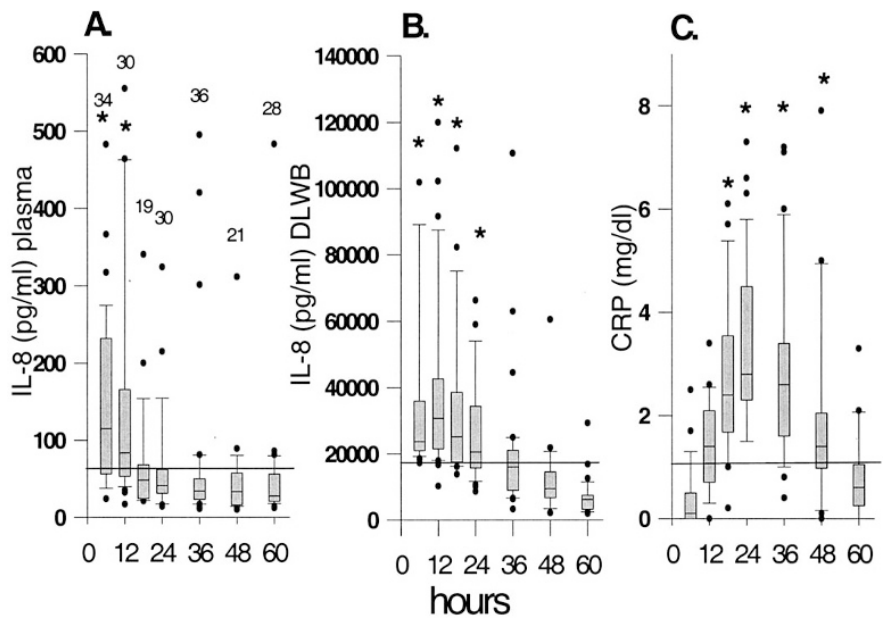

Figure 2. IL-8 concentrations in plasma $(A)$, DLWB $(B)$, and CRP concentration $(C)$ in 61 term neonates with EOBI. Lines represent the ROCdetermined cutoff of $60 \mathrm{pg} / \mathrm{mL}$ (plasma; $A$ ), $18,000 \mathrm{pg} / \mathrm{mL}$ (DLWB; $B$ ), and 10 $\mathrm{g} / \mathrm{L}$ (CRP; C). ${ }^{*} p<0.05$ vs noninfected group measured at the same time, using two-sample $t$ test for the logarithm of the values.

latter parameter in noninfected full-term neonates (Fig. 1). The rise in DLWB IL-8 with EOBI occurred as early as in plasma, but whereas plasma IL-8 started to decrease again after $12 \mathrm{~h}$, DLWB IL-8 concentrations remained elevated for another $18 \mathrm{~h}$, thereby resulting in a higher sensitivity for EOBI (Figs. 2 and 3). Most important, sensitivity for EOBI was considerably higher ( 0.97 versus 0.71 at $6 \mathrm{~h}$ ) for DLWB than for plasma IL-8, making this parameter seemingly well suited for an early detection of EOBI.

Lysing blood cells with detergents is a simple method of detecting cell-associated IL-8 (22). Recently, a cell lysis solution became commercially available, which allows for a fully automated enzyme immunoassay analysis on the IMMULITE System. The methodologic advantages of the system include a fast sample processing, so the results are available $\sim 50 \mathrm{~min}$ after blood sampling, and the small volume $(50 \mu \mathrm{L})$ of blood required. Both features are prerequisites for successful use in neonates.

Consecutive in vivo kinetics of plasma and DLWB IL-8 were investigated in adult patients who underwent IL-2 immunotherapy. IL-2-induced plasma IL-8 was detectable after 2-4 $\mathrm{h}$ and declined rapidly to undetectable within $8 \mathrm{~h}$. Compared with plasma, DLWB IL-8 concentrations were higher, increased as rapid as in plasma, and remained elevated for a longer interval (26), characteristics also found in the present study.

Previous studies on IL-8 in DLWB revealed a critical dependence on preanalytic sample handling $(17,22)$. Much more than circulating IL-8, DLWB IL-8 is affected by blood storage conditions between time of collection and further processing. Whereas storage up to $48 \mathrm{~h}$ on ice caused no increase in DLWB IL-8, storage at room temperature led to a significant increase ex vivo, which amounted to $20 \%$ after $3 \mathrm{~h}$ (17) and up to $45 \%$ after $12 \mathrm{~h}$, whereas the increase in plasma was undetectable (17) or moderate (unpublished observations). Therefore, a delay in sample handling may cause false-positive results.

Induction of IL-8 expression does not necessarily lead to elevated plasma concentrations, as shown during cardiopulmonary bypass (18). Compared with adult blood, in which $94-$ $96 \%$ of exogenous IL-8 was cell associated (22), we found $99 \%$ of detectable IL- 8 as detergent lysable and $<1 \%$ as plasma IL-8 in neonates. Red blood cells therefore act as a sink for IL-8, thereby potentially influencing its activity. To what extent cell-bound IL-8 may serve as an "IL-8 memory" remains to be investigated.

Previous studies on the diagnostic value of plasma IL-8 in the prediction of EOBI reported this cytokine to be more sensitive but less specific than CRP at the onset of suspected infection $(7,23,27)$. Combining serum IL-8 with CRP improved the sensitivity from 83 to $93 \%$ without losing much specificity (7). Our data show a somewhat lower sensitivity (71\%) for plasma IL-8.

CRP concentrations in serum/plasma increase several hundred-fold in response to bacterial infection but only after $18-24 \mathrm{~h}(24,28,29)$. Serial CRP levels are useful to test the probability of suspected infection. However, a normal CRP (28) and IL-8 concentration at the time of clinical suspicion cannot guide the decision whether to treat, especially if symptoms have a short history. The result could be a constellation whereby EOBI cannot be detected by plasma IL- 8 any more because it already has declined but CRP levels have not yet increased. DLWB IL-8 may close this diagnostic gap.

Although highly predictive, determining plasma IL concentrations as diagnostic tools for the detection of EOBI may be challenging, particularly if the sampling does not occur in the initial phase. Messer et al. (30) observed six patients with negative IL-6 plasma levels in his set of infected neonates, probably after IL-6 had already peaked and returned to basal levels. Similar results were obtained by Buck et al. (31), whereby IL-6 decreased to undetectable levels after $24 \mathrm{~h}$ in the majority of infected neonates. IL-6 and IL-8 kinetics in newborns were found to be similar (11). In contrast to CRP levels, IL-6 (32) and IL-8 (33) concentrations may continuously decrease, even in the presence of an ongoing septic infection.

At the time of clinical suspicion in late-onset neonatal infections, Franz et al. (7) predominantly found increased serum IL-8 levels before CRP elevations became detectable. 

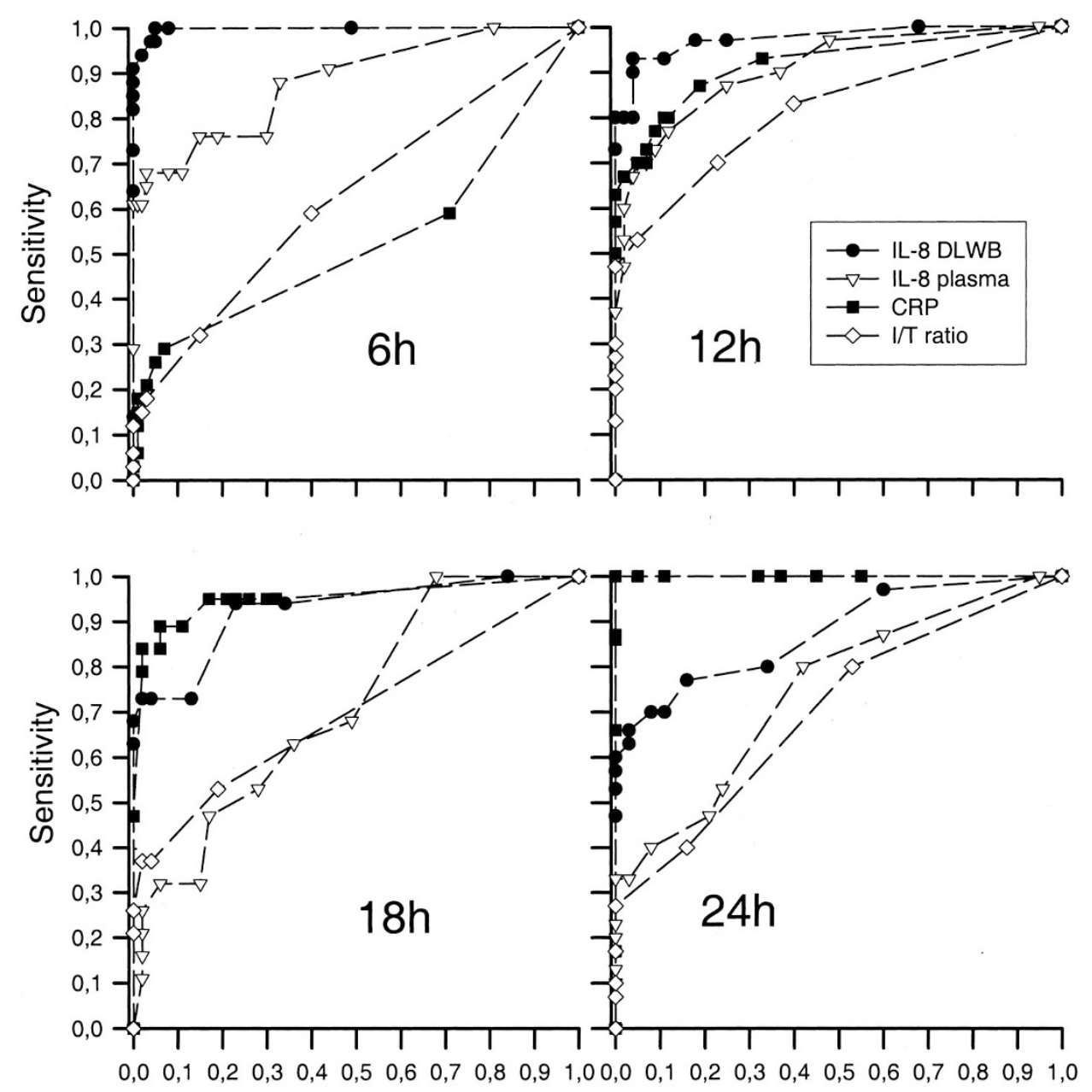

1 - Specifity $\quad 1$ - Specifity

Figure 3. ROC curves for IL-8 in plasma and DLWB, CRP, and I/T ratio after $6,12,18$, and $24 \mathrm{~h}$. Sensitivity is plotted against $1-$ specificity for IL-8 level thresholds between 55 and $70 \mathrm{pg} / \mathrm{mL}$ (plasma) and 17,500 and 19,000 pg/mL (DLWB), CRP plasma level thresholds between 8 and $13 \mathrm{mg} / \mathrm{L}$, and $\mathrm{I} / \mathrm{T}$ ratio thresholds between 0.15 and 0.18 for patients with culture-proven and clinical EOBI.

Table 3. Diagnostic accuracy of plasma and DLWB IL-8, CRP, and IT ratio after $24 \mathrm{~h}$

\begin{tabular}{|c|c|c|c|c|}
\hline & $\begin{array}{c}\text { DLWB IL-8 } \\
>18000 \text { pg/mL }\end{array}$ & $\begin{array}{l}\text { IL-8 plasma } \\
>60 \mathrm{pg} / \mathrm{mL}\end{array}$ & $\begin{array}{c}\text { CRP } \\
>10 \mathrm{mg} / \mathrm{L}\end{array}$ & $\begin{array}{l}\mathrm{I} / \mathrm{T} \text { ratio } \\
\geq 0.2\end{array}$ \\
\hline Sensitivity (\%) & $70(59-81)$ & $33(22-44)$ & $100(97-100)$ & $20(10-30)$ \\
\hline Specificity (\%) & 92 (85-99) & $100(97-100)$ & $95(90-100)$ & $98(96-100)$ \\
\hline PPV (\%) & $88(80-96)$ & $100(97-100)$ & $94(88-100)$ & $100(97-100)$ \\
\hline NPV (\%) & $80(70-90)$ & $66(55-77)$ & $100(97-100)$ & $61(49-73)$ \\
\hline
\end{tabular}

Numbers in parentheses are exact $95 \%$ confidence intervals based on binomial sampling process.

They reported, however, about occasionally normal IL-8 concentrations with (already) elevated CRP, again suggesting delayed detection of infection.

Our investigation again reveals the problem of defining EOBI. Although the clinical course was compatible with EOBI, blood cultures were positive in only two $(3.2 \%)$ patients. This may be due to the consequent implementation of peripartum maternal antibiotic treatment, which makes the diagnostic value of neonatal blood cultures uncertain (34), and that we used very small amounts of blood $(<0.5 \mathrm{~mL})$ in only one culture. The sensitivity of blood cultures in EOBI is low (35) and depends on the number and timing of cultures taken, blood volume, culture medium dilution, technique, tempera- ture, and organism density $(36,37)$. Although only one had a positive blood culture, $24.5 \%$ of our neonates with EOBI were positive for group B streptococci. Estimates of the incidence of group B streptococci EOBI revealed that the true burden of the disease as indicated by culture-proven cases is underestimated, because the latter can be falsely negative in at least $50 \%$ of infants (38).

As in various other studies $(7,35,38)$, the majority of our EOBI group, therefore, consisted of patients defined as "clinically infected neonates" with one or more clinical symptoms, which may, however, be nonspecific, plus alterations in blood parameters, i.e. increased plasma IL-8 or CRP, leukocytosis, leukopenia, or increased I/T ratio. Although the clinical workup was mostly per- 
formed by experienced neonatologists, we are aware of the intrinsic restrictions of this approach, related to heterogeneity of patients, limited comparability to other studies, or dependence on physicians' experience. The CRP cutoff applied in this study (10 $\mathrm{mg} / \mathrm{L}$ ) is also somewhat arbitrary but has been used by several other investigators $(7,24,39)$. Thus, strictly speaking, one could use the term "suspected EOBI" or "clinical EOBI" in the nonculture-proven cases.

In conclusion, the diagnostic value of DLWB IL-8 was superior to plasma IL-8 in this group of neonates with suspected EOBI and combined the advantage of a fast response with a long-lasting difference to noninfected neonates, thereby possibly widening the diagnostic window for EOBI detection by another $12 \mathrm{~h}$. In addition, compared with plasma IL-8, the requested blood volume was reduced by $50 \%$, which makes this parameter particularly attractive for use in preterm neonates.

\section{REFERENCES}

1. Berner R, Niemeyer CM, Leititis JU, Funke A, Schwab C, Rau U, Richter K, Tawfeek MS, Clad A, Brandis M 1998 Plasma levels and gene expression of granulocyte colony-stimulating factor, tumor necrosis factor-alpha, interleukin (IL)- $1 \beta$, IL-6, IL-8, and soluble intercellular adhesion molecule-1 in neonatal early onset sepsis. Pediatr Res 44:469-477

2. Stoll BJ, Gordon T, Korones SB, Shankaran S, Tyson JE, Bauer CR, Fanaroff AA, Lemons JA, Donovan EF, Oh W, Stevenson DK, Ehrenranz RA, Papile LA, Verter J, Wright LL 1996 Early-onset sepsis in very low birthweight neonates: a report from the National Institute of Child Health and Human Development Neonatal Research Network. J Pediatr 129:72-80

3. Krediet T, Gerards L, Fleer A, van Stekelenburg G1992 The predictive value of CRP and I/T-ratio in neonatal infection. J Perinat Med 20: 479-485

4. Lehrnbecher T, Schrod L, Rutsch P, Roos T, Martius J, von Stockhausen HB 1996 Immunologic parameters in cord blood indicating early-onset sepsis. Biol Neonate 70:206-212

5. Mehr S, Doyle LW 2000 Cytokines as markers of bacterial sepsis in newborn infants: a review. Pediatr Infect Dis J 19:879-887

6. Fowlie PW, Schmid B 1998 Diagnostic tests for bacterial infection from birth to 90 days - a systematic review. Arch Dis Child Fetal Neonatal Ed 78:F92-F98

7. Franz AR, Steinbach G, Kron M, Pohlandt F 1999 Reduction of unnecessary antibiotic therapy in newborn infants using interleukin- 8 and C-reactive protein as markers of bacterial infections. Pediatrics 104:447-453

8. de Winter RJ, Manten A, de Jong YP, Adams R, van Deventer SJ, Lie KI 1997 Interleukin 8 released after acute myocardial infarction is mainly bound to erythrocytes. Heart 78:598-602

9. Hata T, Kawamura T, Inada K, Fujiwaki R, Ariyuki Y, Hata K, Kitao M 1996 Interleukin-6, interleukin-8, and granulocyte elastase in newborns with fetal distress. Gynecol Obstet Invest 42:174-177

10. Kalfin RE, Engelman RM, Rousou JA, Flack JE 3rd, Deaton DW, Kreutzer DL, Das DK 1993 Induction of interleukin-8 expression during cardiopulmonary bypass. Circulation 88:401-406

11. Martich GD, Danner RL, Ceska M, Suffredini AF 1991 Detection of interleukin-8 and tumor necrosis factor in normal humans after intravenous endotoxin: the effect of anti-inflammatory agents. J Exp Med 173:1021-1024

12. Redl H, Schlag G, Bahrami S, Schade U, Ceska M, Stutz P 1991 Plasma neutrophilactivating peptide-1/interleukin-8 and neutrophil elastase in a primate bacteremia model. J Infect Dis 164:383-388

13. Redl H, Schlag G, Bahrami S, Dinges HP, Schade U, Ceska M 1991 Markers of endotoxin related leukocyte activation and injury mechanisms. Prog Clin Biol Res 367:83-100

14. Holmes WE, Lee J, Kuang WJ, Rice GC, Wood WI 1991 Structure and functional expression of a human interleukin-8 receptor. Science 253:1278-1280
15. Murphy PM, Tiffany HL 1991 Cloning of complementary DNA encoding a functional human interleukin-8 receptor. Science 253:1280-1283

16. Darbonne WC, Rice GC, Mohler MA, Apple T, Hebert CA, Valente AJ, Baker JB 1991 Red blood cells are a sink for interleukin 8, a leukocyte chemotaxin. J Clin Invest 88:1362-1369

17. Reinsberg J, Dembinski J, Dorn C, Behrendt D, Bartmann P, van Der Ven H 2000 Determination of total interleukin-8 in whole blood after cell lysis. Clin Chem 46:1387-1394

18. Kalfin RE, Engelman RM, Rousou JA, Flack JE 3rd, Deaton DW, Kreutzer DL, Das DK 1993 Induction of interleukin-8 expression during cardiopulmonary bypass. Circulation 88:401-406

19. Peiper SC, Wang ZX, Neote K, Martin AW, Showell HJ, Conklyn MJ, Ogborne K, Hadley TJ, Lu ZH, Hesselgesser J Horuk R 1995 The Duffy antigen/receptor for chemokines (DARC) is expressed in endothelial cells of Duffy negative individuals who lack the erythrocyte receptor. J Exp Med 181:1311-1317

20. Lachgar A, Jaureguiberry G, Le Buenac H, Bizzini B, Zagury JF, Rappaport J, Zagury D 1998 Binding of HIV-1 to RBCs involves the Duffy antigen receptors for chemokines (DARC). Biomed Pharmacother 52:436-439

21. Hesselgesser J, Chitnis CE, Miller LH, Yansura DG, Simmons LC, Fairbrother WJ, Kotts C, Wirth C, Gillece-Castro BL, Horuk R 1995 A mutant of melanoma growth stimulating activity does not activate neutrophils but blocks erythrocyte invasion by malaria. J Biol Chem 270:11472-11476

22. Marie C, Fitting C, Cheval C, Losser MR, Carlet J, Payen D, Foster K, Cavaillon JM 1997 Presence of high levels of leukocyte-associated interleukin-8 upon cell activation and in patients with sepsis syndrome. Infect Immun 65:865-871

23. Franz AR, Kron M, Pohlandt F, Steinbach G 1999 Comparison of procalcitonin with interleukin 8, C-reactive protein and differential white blood cell count for the early diagnosis of bacterial infections in newborn infants. Pediatr Infect Dis J 18:666-671

24. Mathers NJ, Pohlandt F 1987 Diagnostic audit of C-reactive protein in neonatal infection. Eur J Pediatr 146:147-2151

25. Zweig MH, Campbell G 1993 Receiver-operating characteristics (ROC) plots: a fundamental evaluation tool in clinical medicine. Clin Chem 39:561-577

26. Tilg H, Shapiro L, Atkins MB, Dinarello CA, Mier JW 1993 Induction of circulating and erythrocyte-bound IL- 8 by IL-2 immunotherapy and suppression of its in vitro production by IL-1 receptor antagonist and soluble tumor necrosis factor receptor (p75) chimera. J Immunol 151:3299-23307

27. Edgar JD, Wilson DC, McMillan SA, Crockard AD, Halliday MI, Gardiner KR Rowlands BJ, Halliday HL, McNeill TA 1994 Predictive value of soluble immunological mediators in neonatal infection. Clin Sci (Lond) 87:165-171

28. Benitz WE, Han MY, Madan A, Ramachandra P 1998 Serial serum C-reactive protein levels in the diagnosis of neonatal infection. Pediatrics 102:E41

29. Berner R, Tuxen B, Clad A, Forster J, Brandis M 2000 Elevated gene expression of interleukin-8 in cord blood is a sensitive marker for neonatal infection. Eur J Pediatr 159:205-210

30. Messer J, Eyer D, Donato L, Gallati H, Matis J, Simeoni U 1996 Evaluation of interleukin-6 and soluble receptors of tumor necrosis factor for early diagnosis of neonatal infection. J Pediatr 129: 574-2580

31. Buck C, Bundschuh J, Gallati H, Bartmann P, Pohlandt F 1994 Interleukin-6: sensitive parameter for the early diagnosis of neonatal bacterial infection. Pediatrics 93:54-258

32. Hack CE, De Groob ER, Felt-Bersma RJ, Nujjens JH, Strade Van Schijndel RJ, Eerenberg-Belmer AJ, Thijs LG, Aarden LA 1989 Increased plasma levels of interleukin-6 in sepsis. Blood 74:1704-21710

33. Hack CE, Hart M, van Schijndel RJ, Eerenberg AJ, Nuijens JH, Thijs LG, Aarden LA 1992 Interleukin-8 in sepsis: relation to shock and inflammatory mediators. Infect Immun 60:2835-22842

34. Hsu KK, Pelton SI, Shapiro DS 2003 Detection of group B streptococcal bacteremia in simulated intrapartum antimicrobial prophylaxis. Diagn Microbiol Infect Dis 45:23-227

35. Ottolini MC, Lundgren K, Mirkinson LJ, Cason S, Ottolini MG 2003 Utility of complete blood count and blood culture screening to diagnose neonatal sepsis in the asymptomatic newborn. Pediatr Infect Dis J 22:430-2434

36. Kumar Y, Qunibi M, Neal TJ, Yoxall CW 2001 Time to positivity of neonatal blood cultures. Arch Dis Fetal Neonatal Ed 85:F182-F186

37. Buttery JP 2002 Blood cultures in newborn and children: optimising an everyday test. Arch Dis Child Fetal Neonatal Ed 87:F25-F228

38. Luck S, Torny M, d'Agapeyeff K, Pitt A, Heath P, Breathnach A, Russell AB 2003 Estimated early-onset group B streptococcal neonatal disease. Lancet 361:195321954

39. Hengst JM 2003 The role of C-reactive protein in the evaluation and management of infants with suspected sepsis. Adv Neonatal Care 3:3-213 